\title{
СТРОЕНИЕ И ВУЛКАНИЗМ ЗОНЫ СУБДУКЦИИ НА КАМЧАТКЕ
}

\author{
(C) 2022 г. Академик РАН Е. И. Гордеев ${ }^{1, *}$, О. В. Бергаль-Кувикас ${ }^{1}$ \\ Поступило 21.09.2021 г. \\ После доработки 11.10.2021 г. \\ Принято к публикации 12.10.2021 г.
}

\begin{abstract}
Рассмотрена корреляция параметров субдуцирующей плиты с проявлением вулканизма. Увеличение возраста плиты с севера на юг контролирует угол погружения, скорость движения плиты, протяженность сейсмофокальной зоны и отражается в условиях формирования вулканических поясов. Плиоцен-четвертичные вулканы Центрально-Камчатской депрессии имеют преимущественно основной, средний состав магм, в то время как неоген-четвертичный вулканизм Южной Камчатки характеризуется мощными эксплозиями кислых магм. Трансформные разломы формируют гетерогенность плиты, что отражается в большей продуктивности вулканизма относительно фоновых значений вдоль дуги. Существует взаимосвязь между составом магм, высотой вулканов и глубинами магматических очагов.
\end{abstract}

Ключевые слова: субдукция, вулканизм, Камчатка, продуктивность вулканизма, магматические очаги DOI: $10.31857 / \mathrm{S} 2686739722020086$

Детальное строение зоны субдукции на Камчатке впервые было представлено в 1985 г., по распределению гипоцентров землетрясений, определенных по результатам наблюдений Камчатской региональной сети сейсмических станций за период с 1962 по 1981 г. [1]. В этой работе была построена геометрия сейсмофокальной зоны. Вертикальные разрезы по всей протяженности от юга Камчатки вдоль Восточного вулканического пояса показали однородность зоны субдукции с погружением под углом в $50^{\circ}$ до широты в $55^{\circ}$. Далее к северу были отмечены более пологое погружение сейсмофокального слоя и значительный изгиб в сторону континентальной части полуострова. Также было отмечено постепенное уменьшение глубины гипоцентров землетрясений по направлению к зоне сочленения КурилоКамчатской и Алеутской вулканических дуг. Проекция положения вулканов на сейсмофокальный слой пересекает его верхнюю границу на глубине 100-150 км. В 1997 г. в статье Горбатова и др. [2] строение зоны субдукции было определено по результатам распределения гипоцентров землетрясений за период наблюдений 1962-1990 гг. В этой работе для исследования строения и свойств зоны субдукции использовалось не только распределение сейсмичности, но также анализиро-

\footnotetext{
${ }^{1}$ Институт вулканологии и сейсмологии Дальневосточного отделения Российской академии наук, Петропавловск-Камчатский, Россия

*E-mail:gordeev@kscnet.ru
}

вались механизмы землетрясений и термальные параметры погружающейся литосферной океанической плиты. Были определены возраст, скорость и угол погружения плиты, а также изменения протяженности сейсмоактивной зоны и максимальной глубины гипоцентров землетрясений вдоль зоны субдукции. Все эти параметры представлены на рис. 1. Угол наклона субдукционной плиты с маленькими вариациями остается постоянным до широты в $55^{\circ}$ и составляет $45^{\circ}$. Севернее угол наклона уменьшается до $25^{\circ}$. Зона субдукции с юга на север уменьшается по протяженности от 600-700 до 200 км. Соответственно, уменьшается и максимальная глубина гипоцентров землетрясений из зоны субдукции от 500 до 100 км. Уменьшение глубины или протяженности плиты (слэба) вдоль зоны субдукции с юга на север прямо связано со временем, в течение которого проходила субдукция (т.е. с возрастом субдуцирующей плиты). В работе [2] сделаны оценки возраста плиты и, соответственно, скорость погружения плиты (рис. 1). Скорость погружения монотонно уменьшается с юга на север, в то время как протяженность, глубина гипоцентров и возраст плиты имеют резкие изменения на широте около $53^{\circ}$. Эти изменения связаны с Авачинским трансформным разломом, выделенным по аномалиям магнитного поля [3], и трассирующим границу между сложной структурой Восточного вулканического пояса с разновозрастной аккрецией террейнов на севере и долгоживущей островной дугой на юге Камчатки [5]. Эта зона является южной границей, где оканчиваются структуры 

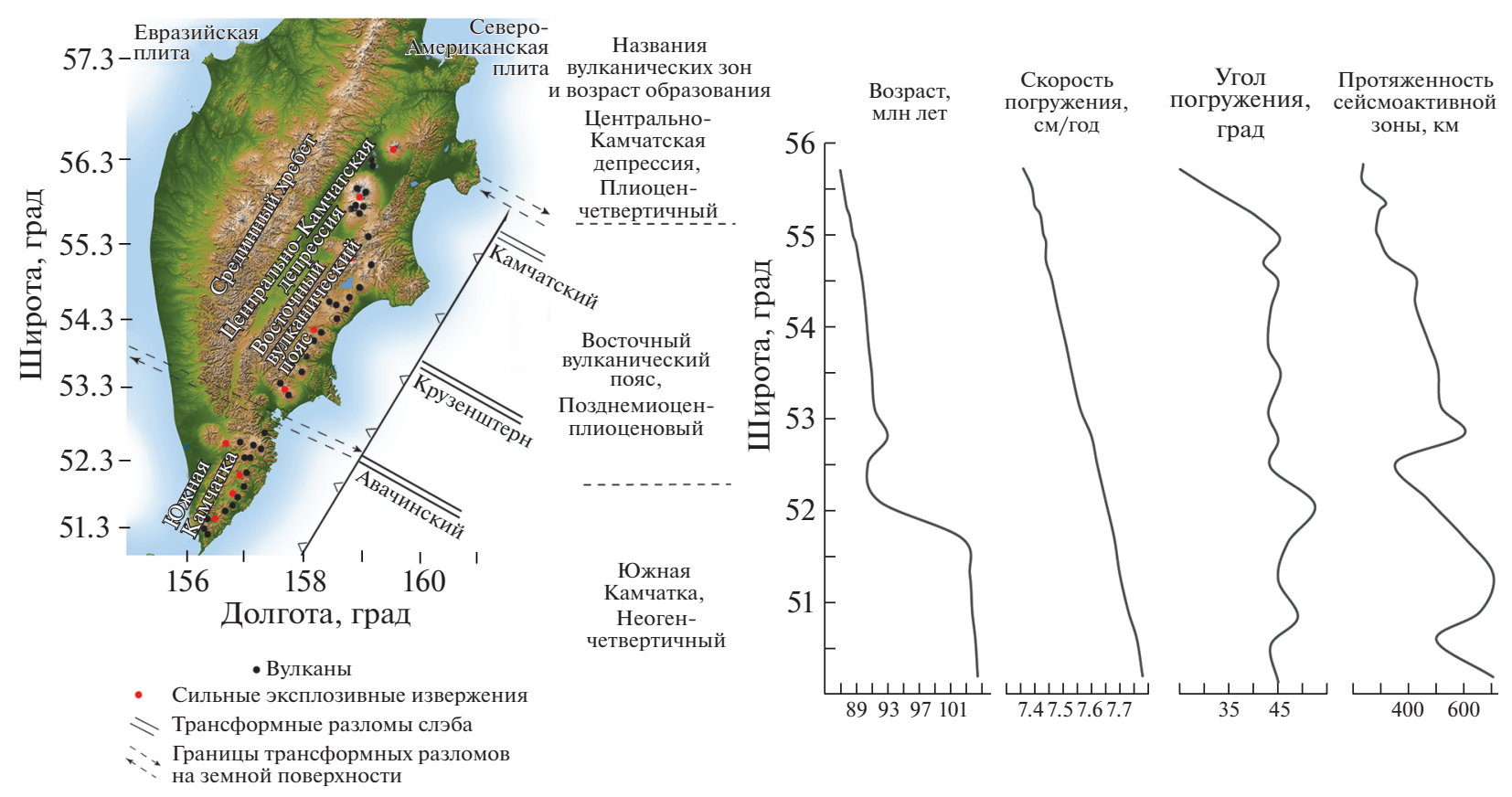

Рис. 1. Параметры субдуцирующей плиты по данным Горбатова [2], расположение трансформных разломов по результатам Андреева [3], сильные эксплозивные извержения по данным Брайцевой и соавт. [4]. Возраст вулканических зон по данным [5, 6].

Срединного хребта и исчезает Центрально-Камчатская депрессия. Продолжением Авачинской разломной зоны на Камчатке является МалкоПетропавловская зона поперечных дислокаций. При переходе через эту зону с юга на север резко уменьшается возраст субдукционной плиты. Структура сейсмоактивной зоны также меняется: уменьшается протяженность сейсмоактивной зоны и, соответственно, максимальная глубина гипоцентров землетрясений. Такие изменения параметров зоны субдукции дают основания полагать, что Авачинский трансформный разлом существует не только в коре, но и в литосфере и нарушает целостность субдукционной плиты (рис. 1).

Самые существенные изменения зоны субдукции на Камчатке проявляются в районе сочленения Курило-Камчатской и Алеутской вулканических дуг. Начиная с $55^{\circ}$ северной широты угол погружения плиты становится более пологим, максимальная глубина землетрясений уменьшается до 100 км и, соответственно, уменьшается протяженность сейсмоактивной зоны (рис. 1). Здесь полностью исчезает субдукционная плита. Как было представлено в работе Левина и др. [7], около 2 млн лет назад северный участок Тихоокеанской литосферной плиты отделился и погрузился в мантию. Возникло окно в зоне стыка Курило-Камчатской и Алеутской островных дуг, и астеносферный поток расплавленного материала в этой зоне начал подниматься к поверхности.
Влияние астеносферного потока вызвало частичное плавление субдукционной плиты на северном участке Курило-Камчатской дуги. Изменение параметров плиты (уменьшение протяженности и угла погружения) связаны с существованием астеносферного потока. В районе сочленения Курило-Камчатской и Алеутской островных дуг также происходит горизонтальный изгиб погружающейся Тихоокеанской плиты и смещение вулканического пояса в сторону континентальной части Камчатки. Эти процессы вызваны влиянием Камчатского трансформного разлома, который возник в западной части Алеутских островов из-за параллельного смещения Тихоокеанской плиты по отношению к СевероАмериканской плите. В этой зоне трансформного разлома существует повышенный тепловой поток, аномальные тела с пониженными значениями скоростей сейсмических волн, приуроченные к рифтовой системе Центрально-Камчатской депрессии [8], а также мантийный плюм, глубина которого достигает 1000 км [9]. Доминирование базальтового состава магм с высокой продуктивностью и большой высотой вулканических построек относительно фоновых значений вдоль дуги (рис. 2) подтверждают существование дополнительных, помимо субдукционных, источников магм в данном сегменте дуги.

Существует общепринятая схема питания вулканов в зонах субдукции, связанная с выплавлением магматических расплавов из мантийного 
клина над субдукционной плитой. Как показано в работе [10], механизм генерации магматических расплавов подобен для различных типов субдукции. Расплав возникает в мантийном клине, на глубине 80-120 км, в зоне проникновения флюидов из субдукционной плиты при температурах выше $1000^{\circ} \mathrm{C}$. Затем расплав в виде диапиров поднимается до границы кора-мантия и образует магматические объемы основного состава. Скорость подъема расплавов в мантийном клине составляет около 1 м/год [10]. Дальнейший подъем магматических расплавов в коре зависит от многих факторов. Несмотря на то что по всей протяженности вдоль дуги генерация расплавов на верхней границе плиты происходит, практически, в одинаковых условиях, и, соответственно, производительность единицы площади плиты не должна меняться вдоль плиты, выход магмы на поверхность земли определяется неоднородным строением коры. Такими неоднородностями являются разломные зоны. По таким ослабленным зонам магматические расплавы достигают поверхности и формируют вулканические постройки. Зафиксированы две зоны повышенной продуктивности вулканов, в районе от $54.5^{\circ}$ до $55.2^{\circ}$ и в районе $53.2^{\circ}-54^{\circ}$ (рис. 2). Первая зона находится в продолжении разлома Крузенштерна, вторая, по всей видимости, опосредованно связана с Авачинским разломом. Таким образом, несмотря на достаточно однородное строение зоны субдукции на Камчатке до широты в $55^{\circ}$ с.ш., существуют значительные неоднородности в вулканической активности. Две зоны повышенной активности связаны с трансформными разломами в земной коре. По существующим представлениям количество магматических расплавов для погружающейся плиты зависит от насыщенности плиты водными флюидами, от состава мантийного клина над плитой и от температуры в этой части мантийного клина, достаточной для плавления вещества [10]. Такие условия должны быть одинаковыми для однородной плиты и, соответственно, продуктивность вулканической деятельности не должна сильно отличаться вдоль вулканической дуги. На самом деле продуктивность северного участка дуги значительно превышает продуктивность на участке дуги южнее широты в $53^{\circ}$. Таким образом, систему образования и распространения магматических расплавов можно рассматривать следующим образом. На верхней границе субдуцирующей плиты в мантийном клине, на глубинах 80-120 км образуются расплавы, которые в виде диапиров поднимаются до границы кора-мантия и накапливаются в виде магматических объемов основного состава. Дальнейший подъем этих расплавов происходит в коре, где формируются как сквозные каналы питания, так и питание из промежуточных очагов, которые формируются в коре. Для магмы в промежуточ-
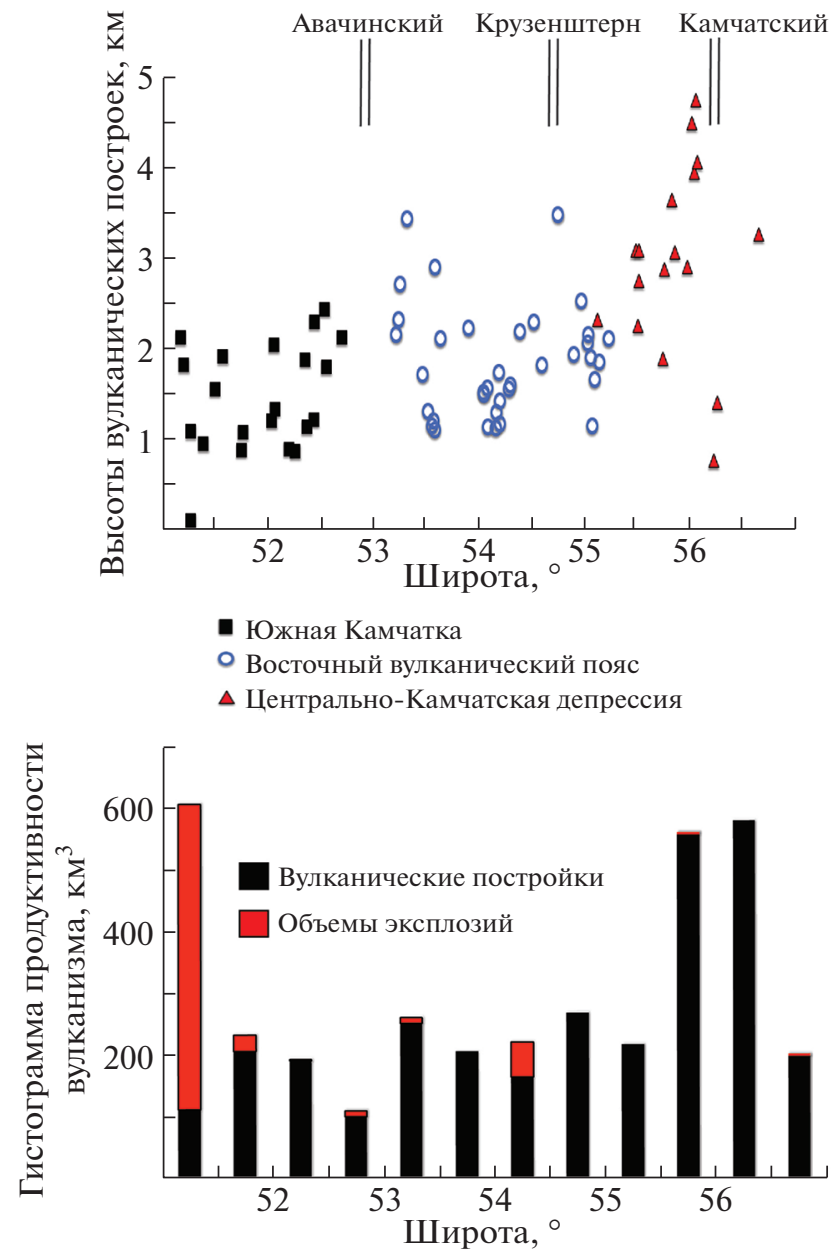

Рис. 2. Вариации вулканизма вдоль дуги. Высоты вулканических построек и продуктивность отдельных вулканических центров по данным [11, 12]. Объемы эксплозий по данным [4]. Расположение трансформных разломов по данным Андреева [3].

ных очагах существует вариант обогащения кислыми силикатными расплавами из вещества коры, а также разделение кислых и основных расплавов в результате дифференциации магмы в промежуточных очагах. Кроме расплавов, образованных на верхней границе субдуцирующей плиты в северной части вулканической дуги, существует дополнительное питание от мантийного восходящего потока на границе слэба. Также на продуктивность вулканов и состав изверженных пород может влиять проникновение мантийного материала через разрывные нарушения, существующие в зоне трансформных разломов. Скорее всего, повышенная продуктивность Авачинско-Корякской группы вулканов и моногенный ареальный вулканизм в Малко-Петропавловской зоне поперечных дислокаций связаны с существованием Авачинского трансформного разлома. 


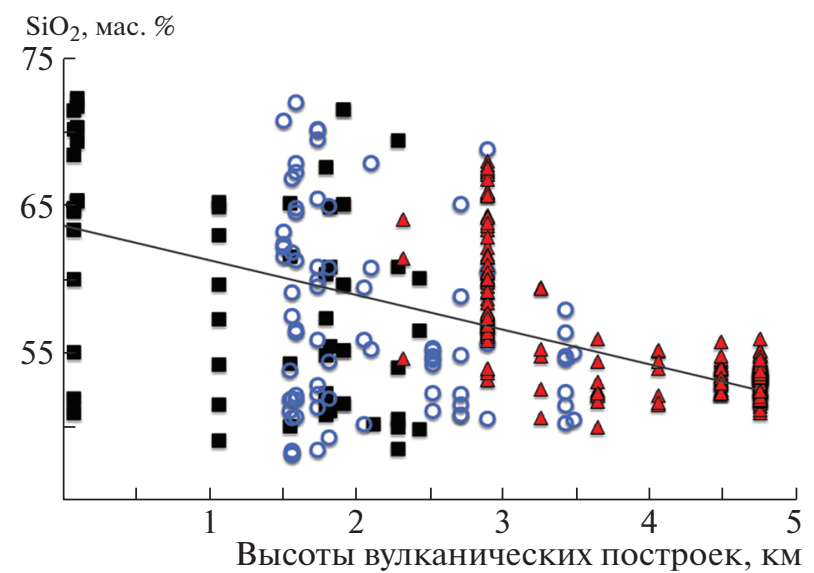

Глубины магматических очагов, км

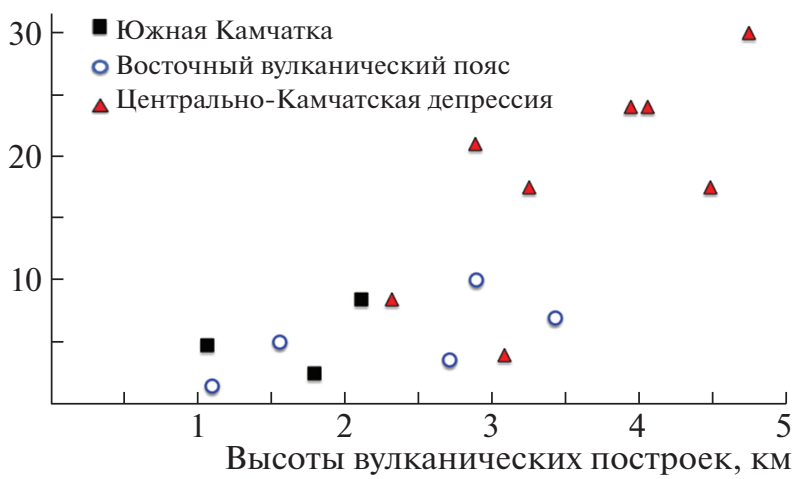

Рис. 3. Зависимость высот вулканических построек от состава магм и глубин нахождения магматических очагов. Геохимический состав магм из базы данных EarthChem. Глубины магматических очагов по многочисленным данным термобарометрических исследований и результатам мантийной томографии.

Скорость подъема магматических расплавов в коре связана с плотностью расплавов, которая определяется содержанием растворенных газов и насыщенностью флюидами. Если расплавы теряют воду, то скорость подъема уменьшается, и такие расплавы могут формировать захороненные магматические тела. С другой стороны, в коре с большой мощностью возникают долгоживущие магматические объемы, где происходит дифференциация, и более легкие кислые магмы накапливаются в верхней части таких объемов, которые могут вызывать мощные эксплозивные извержения. Доминирование эксплозивных извержений на Южной Камчатке относительно Восточного вулканического пояса и Центрально-Камчатской депрессии объясняется более древней историей формирования дуги на мощном кристаллическом фундаменте (рис. 1, 2).

В работе Каструччо и др. [13] определена зависимость высоты вулканических построек от глубины положения магматических очагов. Было показано, что высокие вулканы должны иметь глубинные системы питания по сравнению с более низкими. Такие расчеты были получены из оценки давления в магматических камерах по физико-химическим параметрам магматических расплавов и окружающей среды. Высокие вулканы в зонах субдукции имеют, в основном, базальт-андезитовый состав магм и питаются из глубинных мантийных источников, расположенных у подошвы коры, в то время как низкие вулканы, характеризующиеся более кислыми составами магм, имеют промежуточные магматические камеры в коре.

Для голоцен-плейстоценовых вулканов Камчатки зависимость состава изверженных продуктов от высоты вулканических построек показывает, что для более высоких вулканов, сконцентрированных в Центрально-Камчатской депрессии, состав пород является преимущественно базальтовым, магматические очаги находятся на границе кора-мантия. Вулканы, имеющие андезидацитовый состав магм, как правило, имеют более низкие высоты построек и глубины нахождения магматических очагов до 10 км (рис. 3). Длительное нахождение магм в коре приводит к контаминации, ассимиляции магм осадочными толщами и фракционированию с формированием кислых магматических расплавов с газовой составляющей. Именно этим объяснимо доминирование эксплозивных, мощных извержений на Южной Камчатке, где локализовано большинство кальдерных комплексов Камчатки. По предыдущим исследованиям мощности коры на Камчатке с использованием метода обменных волн (Receiver function) было показано, что толщина коры вдоль зоны субдукции увеличивается с севера на юг от 30 до 40 км на Южной Камчатке [15]. Более мощная кора создает условия для возникновения промежуточных магматических очагов.

Проявление вулканизма на поверхности тесно связано со структурой зоны субдукции и коры. Для более детальных построений систем генерации и транспортировки магматических расплавов необходимо проводить масштабные сейсмотомографические исследования.

\section{ИСТОЧНИК ФИНАНСИРОВАНИЯ}

Работа выполнена за счет гранта Российского научного фонда № 21-17-00049, https://rscf.ru/project/2117-00049.

\section{СПИСОК ЛИТЕРАТУРЫ}

1. Федотов С.А., Гусев А.А., Чернышева Г.В. и др. Сейсмофокальная зона Камчатки (геометрия, размещение очагов землетрясений и связь с вулканизмом) // Вулканология и сейсмология. 1985. № 4. C. $91-107$. 
2. Gorbatov A., Kostoglodov V., Suarez G., et al. Seismicity and Structure of the Kamchatka Subduction Zone // J. Geophys. Res. 1997. V. 102. № B8. P. 17 883-17 898.

3. Андреев A.A. Трансформные разломы земной коры северо-запада Тихого океана // Тихоокеанская геология. 1993. № 3. С. 14-20.

4. Braitseva O., Ponomareva V., Sulerzhitsky L., et al. Holocene Key-marker Tephra Layers in Kamchatka, Russia // Quaternary Research. 1997. 47 (2). P. 125-139. https://doi.org/10.1006/qres.1996.1876

5. Авдейко Г.П., Савельев Д.П., Попруженко С.В., Палуева A.A. Принцип актуализма: критерии для палеотектонических реконструкций на примере Курило-Камчатского региона // Вестник КРАУНЦ. Науки о земле. 2003. №. 1. С. 32-59.

6. Иванов Б.В., Попруженко С.В., Апрелков С.Е. Глубинное строение Центрально-Камчатской депрессии и структурная позиция вулканов // Геодинамика и вулканизм Курило-Камчатской островодужной системы. Петропавловск-Камчатский: ИВГИГ ДВО РАН. 2001. С. 45-57.

7. Levin V., Shapiro N., Park J., et al. Seismic Evidence for Catastrophic Slab Loss Beneath Kamchatka // Nature. 2002. 418 (6899). P. 763-767. https://doi.org/10.1038/nature00973

8. Koulakov I., Shapiro N., Sens-Shoenefelder C., et al. Mantle Sources of Magmatic Activity in the Northern Group of Volcanoes in Kamchatka Inferred from Earthquake Tomography // J. Geophys. Res. Solid
Earth. 2020. https://doi.org/10.1029/2020JB020097

9. Gorbatov A., Fukao F., Widiyantoro S., et al. Seismic Evidence for a Mantle Plume Oceanwards of the Kamchatka-Aleutian Trench Junction // Geophys. Journ. Int. 2001. 146. P. 282-288. https://doi.org/10.1046/j.0956-540x.2001.01439.x

10. Stern R.J. Subduction Zones // Rev. Geophys. 2002. 40 (4). P. 3-38 https://doi.org/10.1029/2001RG000108

11. Гордеев Е.И., Кулаков И.Ю., Шапиро Н.М. Особенности субдукции в зоне сочленения Курило-Камчатской и Алеутской островных дуг // ДАН. Науки о Земле. 2020. 494. № 2. С. 31-36. https://doi.org/10.31857/S2686739720100059

12. Grosse P., Fuillades P., Eullades L., et al. A Global Data Base of Composite Volcano Morphometry // Bulletin of Volcanology. 2014. 76. №. 1. P. 1-16. https://doi.org/10.1007/s00445-013-0784-4

13. Castruccio A., Diez M., Gho R. The Influence of Plumbing System Structure on Volcano Dimensions and Topography // J. Geophys. Res. Solid Earth. 2017. 122. P. 8839-8859. https://doi.org/10.1002/2017JB014855

14. EarthChem. Доступнопо: https://www.earthchem.org.

15. Levin V., Park J., Brandon M., et al., Crust and Upper Mantle of Kamchatka from Teleseismic Receiver Functions // Tectonophysics. 2002. V 358. P. 233-265.

\title{
STRUCTURE OF SUBDUCTION ZONE AND VOLCANISM ON KAMCHATKA
}

\author{
Academician of the RAS E. I. Gordeev ${ }^{a, \#}$ and O. V. Bergal-Kuvikas ${ }^{a}$ \\ ${ }^{a}$ Institute of Volcanology and Seismology, Far East Branch, Russian Academy of Sciences, \\ Petropavlovsk-Kamchatsky, Russian Federation \\ ${ }^{\#}$ E-mail: gordeev@kscnet.ru
}

\begin{abstract}
The correlation of subducted plate parameters with generated volcanism was studied. From north to south increased slab age controls dip angle, rates, and length of seismic slab activities, which are reflected in the development of volcanic belts. Quaternary-Pliocene volcanoes in Central Kamchatkan Depression have basicintermediate magma compositions. In contrast, Neogene-Quaternary volcanism on Southern Kamchatka characterizes by strong explosions of acidic magmas. Transform faults form plate heterogeneity and focus higher magma productivity relative to background values along the arc. Thus, they are a relationship between the magma compositions, the heights of volcanoes, and magma chambers' depths.
\end{abstract}

Keywords: subduction, volcanism, Kamchatka, magma productivity, magma chambers 